\title{
BALIDASYON AT PAGTANGGAP NG INTERAKTIBONG SUPPLEMENTAL NA MODYUL SA PAGGANAP NG MGA MAG-AARAL
}

\author{
Mikee Garcia \\ Teacher, Lucban Academy, Lucban, Quezon
}

Article DOI: https://doi.org/10.36713/epra7748 DOI No: 10.36713/epra7748

\begin{abstract}
ABSTRAK
Ang pag-aaral na ito ay may titulong "BALIDASYON AT PAGTANGGAP NG INTERAKTIBONG SUPPLEMENTAL NA MODYUL SA PERFORMANS NG MGA MAG-AARAL". Layunin ng pag-aaral na ito na mabatid ang kabisaan ng supplemental na kagamitan bilang pantulong sa pagtuturo ng asignaturang Filipino sa mga mag-aaral ng ikapitong baitang sa Taong Panuruan 2020-2021.

Naisin din ng pag-aaral na ito na mabatid ang antas ng paggamit ng modyul bilang pantulong sa pagtuturo ng asignaturang Filipino batay sa nilalaman, kaugnayan, hikayat sa gagamit, pagkakaayos at kahalagahan; malaman ang antas ng pagkatuto ng mga mag-aaral sa asignaturang Filipino batay sa paunang pagsusulit at panapos na pagsusulit; malaman kung may makabuluhang pagkakaiba ang antas ng pagkatuto ng mga mag-aaral batay sa pauna at panapos na pagsusulit; at mabatid kung mayroon bang makabuluhang relasyon ang paggamit ng modyul bilang supplemental na kagamitan sa pagtuturo ng asignaturang Filipino sa pagkatuto ng mga mag-aaral.

Ang pananaliksik na ito ay isinagawa upang makabuo ng kagamitang panturo sa ikaapat na markahan ng asignaturang Filipino bilang kagamitan na makatutulong sa pagpapaunlad sa proseso ng pagtuturo ng guro at pagkatuto ng mag-aaral. Nilayon ng pag-aaral na malaman ang lebel ng pagtanggap ng guro at mag-aaral sa modyul. Ito ay isang kwantitatibong pag-aaral at gumamit ng deskriptibong pananaliksik na ginamitan ng talatanungan sa anyong mga tanong at checklist. Ginamit sa pananaliksik na ito ang purposive sampling sa pagpili ng mga tagasagot mula sa mag-aaral at guro para sa pagtanggap ng materyal mula sa Lucban Academy. Ang weighted mean ay ginamit ng mananaliksik bilang pamamaraang estadistika upang matukoy ang lebel ng pagtanggap sa binuong modyul bilang supplemental na kagamitan. Batay sa kinalabasan ng pananaliksik, ang modyul ay lubos na katanggap-tanggap batay sa nilalaman, kaugnayan, hikayat sa gagamit, pagkakaayos at kahalagahan. Ang mga mag-aaral na nakagamit ng binuong supplemental na modyul ay nadagdagan ang kaalaman pagdating sa paksa, mas naipaliwanag nila ang saloobin hingil sa inaaral na mga aralin at naging makabuluhan ang kasagutan na may tumpak na sagot. Sa pagtanggap ng mga guro sa modyul at pagpapagamit sa mga mag-aaral, mas tumaas ang performans ng mga mag-aaral at naging interaktibo ang mga aralin sa ikaapat na markahan sa Filipino. Lubos na mas magiging malawak ang pagkatuto ng mga mag-aaral kung ang modyul na binuo ay ipapagamit pa sa susunod na markahan o baitang.

Nangangahulungan lamang na ang kagamitang modyul ay isang mabisang kagamitang panturo na maaring magamit sa pagtalakay ng mga aralin. Nabuo ang mungkahi na sa susunod na pananaliksik ay ipagamit sa guro at mag-aaral ang modyul upang maging gabay sa aralin at maaari pang bumuo ng modyul o iba pang supplemental na kagamitan para sa ibang baitang o ibang markahan na maaaring gamitin sa pagtuturo at pagkatuto upang maging interaktibo ang talakayan
\end{abstract}




\section{SJIF Impact Factor 2021: 8.013| ISI I.F.Value:1.241| Journal DOI: 10.36713/epra2016 $\quad$ ISSN: 2455-7838(Online) EPRA International Journal of Research and Development (IJRD)

\section{PANIMULA}

Ipinahayag ni Merculio (2014) sa artikulo na "Media text: A new form of literacy instruction," na ang midya ay hindi lamang para sa pang-aliw ng tagapanood. Makikita rin ang kapakinabangan nito pagdating sa pagkatuto ng mga mag-aaral maging ng mga guro na rin lalo pa't sa kasalukuyang panahon na nabubuhay tayo sa digital na kapaligiran. Sa makatuwid, lahat tayo ay sangkot sa pagbabagong nagaganap sa ating kapaligiran dulot ng integrasyon ng teknolohiya. Ngunit hindi dahil teknolohiya ang uso ay ito na lang ang ating gagamitin at tatangkilin sa pag-aaral, huwag nating kalimutang gumamit pa rin ng mga pulyetos,modyul at iba pang libro na dala na rin ng pagbabago ang nilalaman.

Sa karanasan ng mananaliksik sa pagtuturo sa pribadong paaralan na gumagamit ng libro bilang pangunahing materyal sa kagamitang panturo hindi maikakailang kulang ang o hindi sapat ito upang maging interaktibo ang klase. Nangangailangan pa rin ng mga dagdag na kagamitan upang mas lalong maging mainam ang talakayan lalo't ang mga bata sa panahon ngayon na Online Class ay naging maikli ang atensyon sa pag-aaral sa harap ng computer. Naging malaking hamon ito sa mananaliksik at sa iba pang guro lalo na sa larangan ng asignaturang Filipino kung saan maraming panitikan ang kailangang ituro at basahin, maging sa gramatika at wika na malalim ang talakayan.

Ang mga ito ang nagbigay ideya sa mananaliksik upang magsagawa ng pag-aaral ukol sa kagamitang pampagkatuto na kinakaharap ng mga mag-aaral sa Baitang 7 ng Lucban Academy upang maibigay ang kinakailangang materyal sa pagkatuto. Napagpasyahan ng mananaliksik na sa Lucban Academy isagawa ang pagaaral sapagkat nakita niya ang pangangailangan sa dagdag na kagamitan ng mga kaguruan at mga mag-aaral upang sa ganoon mabigyan ng solusyon ang suliranin sa kagamitan sa pamamagitan ng paggawa ng modyul bilang supplemental na kagamitan sa pagtuturo sa Filipino. Sa kagamitang ito ay matutulungan ang mga guro at mag-aaral upang maging kasiya-siya ang talakayan. Bubuo ang mananaliksik ng modyul upang maging isa pang materyal na magagamit sa talakayan sa asignaturang Filipino. Na sa ganitong paraan ay maging siksik at makabuluhan ang pagaaral sa mga kabanata ng ikaapat na markahan sa Filipino.

\section{Paglalahad ng Suliranin}

Ang pag-aaral na ito ay naglalayong matukoy ang kabisaan ng modyul bilang supplemental na kagamitan na maaaring magamit pantulong sa pagtuturo sa Filipino 7.

Bilang bahagi ng pag-aaral ninanais ng mananaliksik na matamo ang mga sumusunod na layunin:

1. Ano ang antas ng balidasyon at pagtanggap sa Interaktibong Supplemental Modyul batay sa mga sumusunod:
1.1Nilalaman;
1.2 Kaugnayan;
1.3 Hikayat sa Gagamit;
1.4 Pagkakaayos; at
1.5 Kahalagahan?

2. Ano ang antas ng Pagganap ng mga Mag-aaral sa Asignaturang Filipino batay sa pauna at panapos na pagsusulit?

3. Mayroon bang makabuluhang pagkakaiba ng antas ng Pagganap ng mga mag aaral batay sa pauna at panapos na pagsusulit?

4. Mayroon bang makabuluhang relasyon ang balidasyon at pagtanggap sa Interaktibong Supplemental Modyul at Pagganap ng mga Mag-aaral?

\section{METODOLOHIYA NG PANANALIKSIK}

Ang kabanatang ito ay nagsasaad ng pamamaraang ginamit ng mananaliksik upang maisagawa ang pagaaral na ito. Inilahad dito ang lugar ng pananaliksik, kung saan isinagawa ang pagpili ng tagasagot, ginamit na instrumento, at paraan ng pagkuha ng mga datos na ginamiti sa pag-aanalisa ng mga datos.

\section{Tagatugon sa Pananaliksik}

Ang nagsilbing tagatugon sa pananaliksik na ito ay mga piling mag-aaral sa baiting pito (7) ng Lucban Academy. Ang mga tagatugon ay may kabuuang isang daan at tatlo (103) na sumagot sa paunang pagsusulit, panapos na pagsusulit at talatanungan na ipinamahagi ng mananaliksik. 


\section{SJIF Impact Factor 2021: 8.013| ISI I.F.Value:1.241| Journal DOI: 10.36713/epra2016 $\quad$ ISSN: 2455-7838(Online) EPRA International Journal of Research and Development (IJRD)}

\section{Sampling Teknik}

Ginamit ng mananaliksik ng purposive sampling sa pagpili ng mga mag-aaral bilang tagasagot kung saan ang mananaliksik ay pumili ng mag-aaral mula Lucban Academy na nag-aaral ng asignaturang Filipino kung saan sila ang nangangailangan ng kagamitang pantulong sa kanilang pagkatuto.

\section{Paraan ng Pananaliksik}

Para sa pangangalap ng datos para sa lebel ng pagtanggap sa binuong materyal ay ipinakita ng mananaliksik sa mga guro ang liham na pinirmahan ng punongguro na magbibigay pahintulot simula una sa mananaliksik na mangalap ng datos sa kanilang paaralan. Hiningi ng mananaliksik ng kooperasyon ng mga guro sa pagsasagot ng talatanungan para sa lebel ng pagtanggap sa binuong modyul. Ipinaliwanag ng mananaliksik ang panuto upang lubos na maunawaan ang kanilang gagawin. Tumagal ang pangangalap ng datos para sa lebel ng pagtanggap ng isang buwan at matapos nito ay tinipon ng mananaliksik ang mga nakalap na datos.

\section{Instrumento ng Pananaliksik}

Ang mananaliksik ay bumuo ng modyul na naglalaman ng mga aralin sa ikaapat na markahan kaugnay ng asignaturang Filipino. Ang ginawang talatanungan ng mananaliksikay ginamit bilang instrument sa pagkalap ng mga kinakailangang datos. Layunin ng talatanungan na makagawa ng pagtataya sa mga tagatugong mag-aaral.

Ang nilalaman ng talatanungan ay sinagutan ng mga mag-aaral. Ang bigat ng karampatang puntos sa kasagutan sa bahaging ito ay ang mga sumusunod:

5- 4.51-5.00 Lubos na Katnggap-tanggap (LK)

4- 3.51-4.00 Katanggap-tanggap (K)

3- 3.51-3.00 Katamtamang Katanggap-tanggap (KK)

2- 2.51-2.00 Di-ganap na Katanggap-tanggap (DK)

1-1.51-1.00 Lubos na Di-katanggap-tanggap (LDK)

\section{Istatistikal na Pamamaraan}

Ang mananaliksik ay gumamit ng pamamaraang estadistika sa pagkalap ng mga datos upang masuri ang pagtanggap sa mga inilahad na mga aralin sa binuong materyal. Para malaman ang antas ng pagtanggap ng mga mag-aaral sa modyul gumamit ang mananaliksik ng Standard mean, deviation.Upang malaman ang resulta ng pauna at panapos na pagsusulit ang ginamit ng mananaliksik ay ang pormulang weighted mean, at upang malaman naman ang pagkakaiba ng resulta ng panimula at panapos na pagsusulit ay gumamit ng frequency percentage. At para malaman din kung may makabuluhang kaugnayan ba ang pagtanggap ng mga mag-aaral sa modyul bilang kagamitang pampagpagkatuto, ang $T$-test ang naging batayan ng mananaliksik.

\section{KINALABASAN, MUNGKAHI, AT KONKLUSYON KINALABASAN}

Ang pag-aaral na ito ay naglayong alamin kung katanggap-tanggap sa mga mag-aaral sa ikapitong baiting ang ang supplemental na modyul bilang kagamitang panturo.

Ginamit ang deskriptibo-kwantitatibong pamamaraan sa pag-aaral na ito. Nakalap ang mga kinakailangang datos sa pamamagitan ng pauna at panapos na pagsusulit bilang instrumento sa pananaliksik. May kabuuang isang daan at tatlo ang mag-aaral na ginamit na tagasagot sa pauna at panapos na pagsusulit at labing isa na guro ang ginamit na tagasagot sa lebel ng pagtanggap na nagmula sa Lucban Academy na pinili sa pamamagitan ng "purporsive sampling." Gumamit ng percentage, at weighted mean upang makuha ang kasagutan sa mga layunin ng pananaliksik. Ang kinalabasan ng pananaliksik ay nilagom batay sa mga tiyak na katanungang nilayong sagutin.

Batay sa kinalabasan, ipinapakita na ang antas ng balidasyon at pagtanggap sa Interaktibong Supplemental Modyul batay sa Nilalaman, Kaugnayan, Hikayat sa Gagamit, Pagkakaayos at Kahalagahan ay may puna na paliwanag na lubos na katanggap-tanggap.

Ang antas ng pagganap ng mga mag-aaral sa asignaturang Filipino batay sa paunang pagsusulit ay may literal na paliwanag na Di-Mahusay. Sa kabilang dako, pinapakita na ang antas ng pagganap ng mga mag-aaral sa asignaturang Filipino batay sa panapos na pagsusulit ay may literal na paliwanag na Malapit at halos pumantay sa Pinakamahusay. Sa datos na nakalap, ipinapakita nito na "may makabuluhang pagkakaiba ang antas ng pagganap ng mga mag-aaral batay sa pauna at panapos na pagsusulit" at antas na may kabuluhan. At ipinapakita din nito na ang 


\title{
SJIF Impact Factor 2021: 8.013| ISI I.F.Value:1.241| Journal DOI: 10.36713/epra2016 ISS: 2455-7838(Online)
}

\section{EPRA International Journal of Research and Development (IJRD)}

\author{
Volume: 6 | Issue: 7 | July 2021
}

- Peer Reviewed Journal

walang bisang palagay na "Walang makabuluhang pagkakaiba ang antas ng pagganap ng mga mag-aaral batay sa pauna at panapos na pagsusulit" ay huwag tanggapin, ipinapakita nito na "may makabuluhang" pagkakaiba sa pagitan nila.

Sa pagtanggap at balidasyon ng binuong materyal, ipinapakita nito na "may makabuluhang kaugnayan ang paggamit ng Supplemental Modyul sa asignaturang Filipino sa pagganap ng mga mag-aaral" at antas ng kabuluhan. At ipinapakita din nito na ang walang bisang palagay na "Walang makabuluhang kaugnayan ng balidasyon at pagtanggap sa Interaktibong Supplemental Modyul at Performans ng mga Mag-aaral” ay huwag tanggapin, ipinapakita nito na "may makabuluhang" kaugnayan sa pagitan nila.

\section{MUNGKAHI}

Batay sa kinalabasan at konklusyon ng pag-aaral, ang mga sumusunod na mungkahi ay binuo ng mananaliksik:

1. Ang modyul o iba pang supplemental na kagamitan sa pagkatuto ng mga mag-aaral ay maaaring ipagamit sa guro sa kanilang pagtuturo at mag-aaral sa talakayan ng aralin upang mas lalong maunawaan ang mga aralin.

2. Maaari pang bumuo ng modyul o iba pang supplemental na kagamitan para sa ibang baitang o ibang markahan na maaaring gamitin sa pagtuturo at pagkatuto upang maging interaktibo ang talakayan.

3. Tumuklas pa ng ibang kagamitan tulad ng babasahin na magagamit sa pagtuturo na nagtataglay ng kaakitakit na disenyo na mauunawaan ng mga mag-aaral at magbibigay ng karagdagang pagkatuto sa kanila.

\section{KONKLUSYON}

1. Mayroong malaking pagkakaiba ang resulta ng pauna at panapos na pagsusulit kung saan sa paunang pagsusulit na wala pang modyul ay limitado lamang ang nalalaman ng mag-aaral at kulang pa ang kakayahang umunawa sa paksa. Salamantalang sa panapos na pagsusulit matapos magamit ang modyul ay makikitang mas naunawaan ng mag-aaral ang mga paksa sa asignaturang Filipino at mataas ang marka nakuha sa pagsusulit gamit ito. Nangangahulugang lubos na may kaibahan ang paggamit ng modyul kumpara sa libro lamang.

2. Ang mga mag-aaral na nakagamit ng binuong supplemental na modyul ay nadagdagan ang kaalaman pagdating sa paksa, mas naipaliwanag nila ang saloobin hingil sa inaaral na mga aralin at naging makabuluhan ang kasagutan na may tumpak na sagot. Sa pagtanggap ng mga guro sa modyul at pagpapagamit sa mga mag-aaral, mas tumaas ang performans ng mga mag-aaral at naging interaktibo ang mga aralin sa ikaapat na markahan sa Filipino. Lubos na mas magiging malawak ang pagkatuto ng mga mag-aaral kung ang modyul na binuo ay ipapagamit pa sa susunod na markahan o baitang.

\section{MGA TALAHANAYAN}

Talahanayan 1. Antas ng balidasyon at pagtanggap sa Interaktibong Supplemental Modyul batay sa Nilalaman

\begin{tabular}{|l|c|c|c|}
\hline MgaPahayag & Mean & SD & Puna \\
\hline $\begin{array}{l}\text { Madaling maunawaan at mabasa ang mga titik at salita sa } \\
\text { modyul. }\end{array}$ & 4.82 & 0.40 & Lubos na katanggap-tanggap \\
\hline Maayos na naihanay ang mga salita at pangungusap. & 4.73 & 0.65 & Lubos na katanggap-tanggap \\
\hline Walang taypograpikal na pagkakamali sa akda at salita. & 4.36 & 0.67 & Lubos na katanggap-tanggap \\
\hline $\begin{array}{l}\text { Wasto ang paglalahad at pagbibigay ng impormasyon sa bawat } \\
\text { aralin. }\end{array}$ & 4.55 & 0.69 & Lubos na katanggap-tanggap \\
\hline $\begin{array}{l}\text { Madaling maunawaan at mabasa ang mga salita sa ginawang } \\
\text { modyul. }\end{array}$ & 4.18 & 1.25 & Katanggap-tanggap \\
\hline $\begin{array}{l}\text { May tamang espasyo para sa impormasyon at aktibidad sa } \\
\text { modyul. }\end{array}$ & 4.55 & 0.82 & Lubos na katanggap-tanggap \\
\hline $\begin{array}{l}\text { Malinaw ang mga larawang nakapaloob sa modyul. } \\
\text { Matatagpuan sa talaan ng nilalaman ang lahat ng aralin na } \\
\text { makikita sa modyul. }\end{array}$ & 4.55 & 0.69 & Lubos na katanggap-tanggap \\
\hline
\end{tabular}




\begin{tabular}{|l|l|l|l|}
\hline $\begin{array}{l}\text { May sapat na pagsasanay at mga katanungan para sa panimula } \\
\text { at mgaaralin ng modyul. }\end{array}$ & 4.64 & 0.67 & Lubos na katanggap-tanggap \\
\hline $\begin{array}{l}\text { Maayos ang pagkakalahad ng mga buod sa kada aralin na } \\
\text { nakapaloob sa modyul. }\end{array}$ & 4.64 & 0.67 & Lubos na katanggap-tanggap \\
\hline $\begin{array}{l}\text { Overall Mean: } 4.58 \\
\text { Standard Deviation: } 0.722 \\
\text { Literal napaliwanag: Lubhang Mataas }\end{array}$ & & \\
\hline
\end{tabular}

Palatandaan

\begin{tabular}{|c|c|c|}
\hline Sukatan & Saklaw & Puna \\
\hline 5 & $4.20-5.00$ & Lubosnakatanggap-tanggap \\
\hline 4 & 3.40-4.19 & Katanggap-tanggap \\
\hline 3 & 2.60-3.39 & $\begin{array}{l}\text { KatamtamangKatanggap- } \\
\text { tanggap }\end{array}$ \\
\hline 2 & $1.80-2.59$ & Hindi katanggap-tanggap \\
\hline 1 & $1.00-1.79$ & $\begin{array}{l}\text { Lubos na Hindi katanggap- } \\
\text { tanggap }\end{array}$ \\
\hline
\end{tabular}

Talahanayan 2. Antas ng balidasyon at pagtanggap sa Interaktibong Supplemental Modyul batay sa Kaugnayan

\begin{tabular}{|l|c|c|c|}
\hline MgaPahayag & Mean & SD & \multicolumn{1}{c|}{ Puna } \\
\hline $\begin{array}{l}\text { Ang mga nakapaloob na gawain ay angkop sa edad at lebel ng } \\
\text { mga tagasagot nito. }\end{array}$ & 4.64 & 0.67 & Lubos na katanggap tanggap \\
\hline $\begin{array}{l}\text { Ang bawat gawain ay angkop sa multiple intelligences ng mga } \\
\text { mag-aaral. }\end{array}$ & 4.55 & 0.82 & Lubos na katanggap-tanggap \\
\hline Ang bawat gawain ay nakabatay sa mga nakalahad na aralin. & 4.55 & 0.69 & Lubos na katanggap-tanggap \\
\hline $\begin{array}{l}\text { Ang ilustrasyong ginamit sa materyal ay naiuugnay sa bawat } \\
\text { gawain. }\end{array}$ & 4.55 & 0.69 & Lubos na katanggap-tanggap \\
\hline $\begin{array}{l}\text { Ang kagamitang ito ay magagamit ng mga guro sa } \\
\text { asignaturang Filipino sa pagtuturo at pagtataya. }\end{array}$ & 4.64 & 0.50 & Lubos na katanggap-tanggap \\
\hline Nakalinya sa MELCS ang mga araling nakapaloob sa modyul. & 4.64 & 0.67 & Lubos na katanggap-tanggap \\
\hline $\begin{array}{l}\text { Ang mga aktibidad ay lumilinang sa pag-ungali ng mga } \\
\text { kabataan na tunguhin ng pag-aaral ng Ibong Adarna. }\end{array}$ & 4.73 & 0.47 & Lubos na katanggap-tanggap \\
\hline $\begin{array}{l}\text { Ang bawat katanungan sa aralin ay sasagot sa natutunan sa } \\
\text { pagtalakay nito. }\end{array}$ & 4.73 & 0.47 & Lubos na katanggap-tanggap \\
\hline $\begin{array}{l}\text { Ang mga pagsasanay na inilaan sa bawat aralin ay tumutugon } \\
\text { sa mga pagtatayang susukat sa kaalaman (Knowledge), } \\
\text { kasanayan (Process), pang-unawa (Understanding), at } \\
\text { pagsasagawa/pagbuo (Performance/Product) na lubhang } \\
\text { mahalaga upang maging ganap at makabuluhan ang } \\
\text { pagkatutuo ng mga mag-aaral. }\end{array}$ & 4.55 & 0.69 & Lubos na katanggap-tanggap \\
\hline $\begin{array}{l}\text { Makatutulong ang modyul sa iba't ibang sitwasyon ng mga } \\
\text { mag-aaral sa pag-aaral lalo't higit ngayong Online Class. }\end{array}$ & 4.64 & 0.50 & Lubos na katanggap-tanggap \\
\hline $\begin{array}{l}\text { Overall Mean: 4.62 } \\
\text { Standard Deviation: 0.606 } \\
\text { Literal napaliwanag: Lubhang Mataas }\end{array}$ & & \\
\hline
\end{tabular}


Palatandaan

\begin{tabular}{|c|c|c|}
\hline Sukatan & Saklaw & Puna \\
\hline 5 & 4.20-5.00 & Lubos na katanggap-tanggap \\
\hline 4 & $3.40-4.19$ & Katanggap-tanggap \\
\hline 3 & 2.60-3.39 & $\begin{array}{l}\text { Katamtamang Katanggap- } \\
\text { tanggap }\end{array}$ \\
\hline 2 & $1.80-2.59$ & Hindi katanggap-tanggap \\
\hline 1 & 1.00-1.79 & $\begin{array}{l}\text { Lubos na Hindi katanggap- } \\
\text { tanggap }\end{array}$ \\
\hline
\end{tabular}

Talahanayan 3. Antas ng balidasyon at pagtanggap sa Interaktibong Supplemental Modyul batay sa Hikayat sa Gagamit

\begin{tabular}{|c|c|c|c|}
\hline MgaPahayag & Mean & SD & Puna \\
\hline $\begin{array}{l}\text { Maganda ang pagkakaayos kung kaya't nakahihikayat na } \\
\text { basahin at alamin ang mga aralin. }\end{array}$ & 4.36 & 0.92 & Lubos na Katanggap-tanggap \\
\hline $\begin{array}{l}\text { May kaakit-akit na disenyo upang makuha ang atensyon ng } \mathrm{mga} \\
\text { babasa at gagamit nito. }\end{array}$ & 4.73 & 0.65 & Lubos na Katanggap-tanggap \\
\hline $\begin{array}{l}\text { Pormal at organisado ang kabuuang laman ng modyul upang } \\
\text { mapukaw ang interes ng mgagagamit. }\end{array}$ & 4.64 & 0.67 & Lubos na Katanggap-tanggap \\
\hline May wastong pormat ang kabuuang modyul. & 4.64 & 0.67 & Lubos na Katanggap-tanggap \\
\hline $\begin{array}{l}\text { Nagingmadali ang pagkaunawa at pagkatuto ng mga mag-aaral } \\
\text { sa mga aralin gamit ang modyul. }\end{array}$ & 4.55 & 0.82 & Lubos na Katanggap-tanggap \\
\hline $\begin{array}{l}\text { Madaling madala kung saan at magamit kung kalian kailangan } \\
\text { ang modyul. }\end{array}$ & 4.64 & 0.67 & Lubos na Katanggap-tanggap \\
\hline $\begin{array}{l}\text { Binibigyang pagkakataon ang mga mag-aaral na maglahad ng } \\
\text { kanilang saloobin hingil sa aralin. }\end{array}$ & 4.73 & 0.47 & Lubos na Katanggap-tanggap \\
\hline $\begin{array}{l}\text { Ang mga pangungusap at mga salita ay binigyang interpreta } \\
\text { upang mabilis maunawaan. }\end{array}$ & 4.64 & 0.67 & Lubos na Katanggap-tanggap \\
\hline $\begin{array}{l}\text { Ang mga aktibidad ay hindi lamang pang indibidwal kundi } \\
\text { mayroong dalawahan o grupo na eengganyo sa mga mag-aaral. }\end{array}$ & 4.73 & 0.47 & Lubos na Katanggap-tanggap \\
\hline $\begin{array}{l}\text { Walang limitasyon ang pagsagot o haba ng kasagutan sa } \\
\text { binuong modyul. }\end{array}$ & 4.64 & 0.67 & Lubos na Katanggap-tanggap \\
\hline \multicolumn{4}{|l|}{$\begin{array}{l}\text { Overall Mean: } 4.63 \\
\text { Standard Deviation: } 0.662 \\
\text { Literal napaliwanag: Lubhang Mataas }\end{array}$} \\
\hline
\end{tabular}

Palatandaan

\begin{tabular}{|c|c|c|}
\hline Sukatan & Saklaw & Puna \\
\hline 5 & 4.20-5.00 & Lubos na katanggap-tanggap \\
\hline 4 & 3.40-4.19 & Katanggap-tanggap \\
\hline 3 & 2.60-3.39 & $\begin{array}{l}\text { Katamtamang Katanggap- } \\
\text { tanggap }\end{array}$ \\
\hline 2 & 1.80-2.59 & Hindi katanggap-tanggap \\
\hline 1 & 1.00-1.79 & $\begin{array}{l}\text { Lubosna Hindi katanggap- } \\
\text { tanggap }\end{array}$ \\
\hline
\end{tabular}




\section{EPRA International Journal of Research and Development (IJRD)}

Talahanayan4. Antas ng balidasyon at pagtanggap sa Interaktibong Supplemental Modyul batay sa Pagkakaayos

\begin{tabular}{|l|c|c|c|}
\hline Mga Pahayag & Mean & SD & Puna \\
\hline Maayos ang mga gawain maging ang panimula ng modyul. & 4.55 & 0.82 & Lubos na Katanggap-tanggap \\
\hline $\begin{array}{l}\text { Organisado ang pagkakaayos ng mga nakapaloob na } \\
\text { pagsasanay. }\end{array}$ & 4.64 & 0.67 & Lubos na Katanggap-tanggap \\
\hline Malinaw ang ibinigay na kahulugan ng mga salita. & 4.82 & 0.40 & Lubos na Katanggap-tanggap \\
\hline $\begin{array}{l}\text { May tamang pagkakasunod-sunod ang mga aralin gayun din } \\
\text { ang mga halimbawa sa modyul. }\end{array}$ & 4.82 & 0.40 & Lubos na Katanggap-tanggap \\
\hline May tamang espasyo para sa aralin at mga pagsasanay. & 4.73 & 0.65 & Lubos na Katanggap-tanggap \\
\hline Ang mga pahina ay sapat para sa kabuuan ng bawat aralin. & 4.64 & 0.67 & Lubos na Katanggap-tanggap \\
\hline Ang mga larawan at desenyo sa modyul ay sapat ang laki. & 4.64 & 0.67 & Lubos na Katanggap-tanggap \\
\hline $\begin{array}{l}\text { Iisa ang sinunod na hanay sa pagbibigay ng buod, kaalaman, } \\
\text { at pagsasanay upang di maghatid ng kalituhan. }\end{array}$ & 4.64 & 0.67 & Lubos na Katanggap-tanggap \\
\hline $\begin{array}{l}\text { Kompleto sa halimbawa, tauhan at kahulugan ng di } \\
\text { maunawaang salita ang laman ng modyul. }\end{array}$ & 4.73 & 0.47 & Lubos na Katanggap-tanggap \\
\hline $\begin{array}{l}\text { Ang mga letra ay may tamang sukat at laki batay sa katuturan } \\
\text { nito sa modyul. }\end{array}$ & 4.64 & 0.81 & Lubos na Katanggap-tanggap \\
\hline $\begin{array}{l}\text { Overall Mean: 4.68 } \\
\text { Standard Deviation: } \mathbf{0 . 6 2 0} \\
\text { Literal napaliwanag: Lubhang Mataas }\end{array}$ & & & \\
\hline
\end{tabular}

Palatandaan

\begin{tabular}{|c|c|c|}
\hline Sukatan & Saklaw & Puna \\
\hline 5 & 4.20-5.00 & Lubos na katanggap-tanggap \\
\hline 4 & $3.40-4.19$ & Katanggap-tanggap \\
\hline 3 & 2.60-3.39 & $\begin{array}{l}\text { Katamtamang Katanggap- } \\
\text { tanggap }\end{array}$ \\
\hline 2 & $1.80-2.59$ & Hindi katanggap-tanggap \\
\hline 1 & $1.00-1.79$ & $\begin{array}{l}\text { Lubos na Hindi katanggap- } \\
\text { tanggap }\end{array}$ \\
\hline
\end{tabular}

Talahanayan 5. Antas ng balidasyon at pagtanggap sa Interaktibong Supplemental Modyul batay sa Kahalagahan

\begin{tabular}{|l|c|c|c|}
\hline Mga Pahayag & Mean & SD & Puna \\
\hline $\begin{array}{l}\text { Mas madali nang nalalaman ang tinatalakay na aralin sa } \\
\text { pamamagitan ng modyul. }\end{array}$ & 4.73 & 0.65 & Lubos na Katanggap-tanggap \\
\hline $\begin{array}{l}\text { Makatutulong ang materyal na ito upang maging kolaboratibo } \\
\text { at kooperatibo ang pagkatuto sa loob ng klase. }\end{array}$ & 4.73 & 0.65 & Lubos na Katanggap-tanggap \\
\hline $\begin{array}{l}\text { Ang mga gawain sa kagamitang ito ay lumilinang ng mga } \\
\text { kakayahan at kasanayang pangkaisipan ng mga mag-aaral. }\end{array}$ & 4.64 & 0.67 & Lubos na Katanggap-tanggap \\
\hline $\begin{array}{l}\text { Ang mga pagsasanay na nakapaloob sa materyal ay } \\
\text { makatutulong upang mahasa pa ang kaalaman ng mga mag- } \\
\text { aaral sa mga makrong kasanayan. }\end{array}$ & 4.64 & 0.67 & Lubos na Katanggap-tanggap \\
\hline $\begin{array}{l}\text { Kapaki-pakinabang ang modyul upang mahasa ang bawat } \\
\text { aralin. }\end{array}$ & 4.82 & 0.40 & Lubos na Katanggap-tanggap \\
\hline $\begin{array}{l}\text { Ang mga Gawain sa modyul ay kakikitaan ng repleksyon ng pag- } \\
\text { uugali ng mga kabataan. }\end{array}$ & 4.82 & 0.40 & Lubos na Katanggap-tanggap \\
\hline
\end{tabular}




\section{EPRA International Journal of Research and Development (IJRD)}

\begin{tabular}{|l|c|c|c|}
\hline $\begin{array}{l}\text { Napapanahon ang mga halimbawang ibinigay sa mga aralin na } \\
\text { mauunawaan ng mga mag-aaral. }\end{array}$ & 4.82 & 0.40 & Lubos na Katanggap-tanggap \\
\hline $\begin{array}{l}\text { Makatutulong ang dagdag na materyal na modyul sa madaling } \\
\text { pagkaunawa sa mga aralin. }\end{array}$ & 4.82 & 0.40 & Lubos na Katanggap-tanggap \\
\hline $\begin{array}{l}\text { Matataya ng mga guro ang kaalaman ng mga mag-aaral sa } \\
\text { pamamagitan ng mga patatayang nakapaloob sa modyul. }\end{array}$ & 4.73 & 0.65 & Lubos na Katanggap-tanggap \\
\hline $\begin{array}{l}\text { Magagamit ng mga mag-aaral na walang kapasidad sa internet } \\
\text { at computer ang inihandang modyul. }\end{array}$ & 4.82 & 0.40 & Lubos na Katanggap-tanggap \\
\hline $\begin{array}{l}\text { Overall Mean: 4.76 } \\
\text { Standard Deviation: } 0.528 \\
\text { Literal napaliwanag: Lubhang Mataas }\end{array}$ & & & \\
\hline
\end{tabular}

Palatandaan

\begin{tabular}{|c|c|c|}
\hline Sukatan & Saklaw & Puna \\
\hline 5 & 4.20-5.00 & Lubos na katanggap-tanggap \\
\hline 4 & $3.40-4.19$ & Katanggap-tanggap \\
\hline 3 & 2.60-3.39 & $\begin{array}{l}\text { Katamtamang Katanggap- } \\
\text { tanggap }\end{array}$ \\
\hline 2 & 1.80-2.59 & Hindi katanggap-tanggap \\
\hline 1 & $1.00-1.79$ & $\begin{array}{l}\text { Lubos na Hindi katanggap- } \\
\text { tanggap }\end{array}$ \\
\hline
\end{tabular}

Talahanayan 6. Antas ng performans ng mga mag-aaral sa asignaturang

Filipino batay sa paunang pagsusulit

\begin{tabular}{|c|c|c|c|c|c|}
\hline Marka & Bilang & Bahagdan & Bilang & Bahagdan & Literal na Paliwanag \\
\hline $29-30$ & 0 & 0.00 & 67 & 65.05 & Pinakamahusay \\
\hline $26-28$ & 2 & 1.94 & 10 & 9.71 & Higit na Mahusay \\
\hline $20-25$ & 4 & 3.88 & 15 & 14.56 & May sapat na husay \\
\hline $17-19$ & 2 & 1.94 & 2 & 1.94 & Mahusay \\
\hline $5-16$ & 42 & 40.78 & 9 & 8.74 & Katamtamang mahusay \\
\hline $2-4$ & 6 & 5.83 & 0 & 0.00 & Di-gaanong mahusay \\
\hline $0-1$ & 47 & 45.63 & 0 & 0.00 & Di-mahusay \\
\hline TOTAL & 103 & 100.00 & 103 & 100.00 & \\
\hline \multicolumn{2}{|c|}{ Weighted Mean } & 5.48 & & 26.38 & \\
\hline \multicolumn{2}{|c|}{ Pinakamababang Marka } & 0 & & 5 & \\
\hline \multicolumn{2}{|c|}{ Pinakamataas na Marka } & 27 & & 30 & \\
\hline \multicolumn{2}{|c|}{ Standard Deviation } & 6.527 & & 6.192 & \\
\hline \multicolumn{2}{|c|}{ Literal na Paliwanag } & Di-mahusay & & $\begin{array}{l}\text { Malapit at halos } \\
\text { pumantay sa } \\
\text { Pinakamahusay }\end{array}$ & \\
\hline
\end{tabular}

\begin{tabular}{ll}
\hline Palatandaan: & \\
Sukatan & Literal na Paliwanag \\
$\mathbf{9 6 \%}-\mathbf{1 0 0 \%}$ & Pinakamahusay \\
$\mathbf{8 6 \%}-\mathbf{9 5 \%}$ & Higit na Mahusay \\
$\mathbf{6 6 \%}-\mathbf{8 5 \%}$ & Mahusay \\
$\mathbf{5 5 \%}-\mathbf{6 5 \%}$ & Katamtamang Mahusay \\
$\mathbf{1 5 \%}-\mathbf{5 4 \%}$ & Di-gaanong Mahusay \\
$\mathbf{5 \%}-\mathbf{1 4 \%}$ & Di-lubhang mahusay \\
$\mathbf{0 \%}-\mathbf{4 \%}$ & Di-mahusay
\end{tabular}

(6) 2021 EPRA IJRD | Journal DOI: https://doi.org/10.36713/epra2016 | www.eprajournals.com |362 | 
Talahanayan 7. Makabuluhang pagkakaiba ng antas ng Performans ng mga Mag-aaral batay sa paunang at panapos na pagsusulit

\begin{tabular}{|l|c|c|c|c|c|}
\hline \multicolumn{1}{|c|}{ Pagsusulit } & Mean & $\begin{array}{c}\text { Computed t- } \\
\text { value }\end{array}$ & $\begin{array}{c}\text { Critical } \\
\text { t-value }\end{array}$ & p-value & Analysis \\
\hline Pauna & 5.48 & 23.5799 & 1.6524 & 0.0000 & Makabuluhan \\
\hline Panapos & 26.38 & & & \\
\hline
\end{tabular}

Talahanayan 8. Makabuluhang Kaugnayan ng Balidasyon at Pagtanggap sa Interaktibong Supplemental Modyul at Performans ng mga Mag-aaral

\begin{tabular}{|l|c|c|c|c|}
\hline & & r-value & Katibayan ng Ugnayan & Analisis \\
\hline $\begin{array}{l}\text { Supplemental } \\
\text { Modyul }\end{array}$ & Performans & 0.1840 & Napakababang pagkakaugnay & Makabuluhan \\
\hline
\end{tabular}

Palatandaan:
Sukatan
Katibayan ng Ugnayan
$\pm \mathbf{0 . 0 0}$
Walang pagkakaugnay, Walang relasyon
$\pm 0.01- \pm 0.20$ Napakababang pagkakaugnay, Halos walang relasyon
$\pm 0.21- \pm 0.40$ Mababang pagkakaugnay, Tiyak ngunit mababaw ang relasyon
$\pm 0.41- \pm 0.70$ Katamtamang pagkakaugnay, Makabuluhan ang relasyon
$\pm 0.71- \pm 0.90$ Mataas na pagkakaugnay, Kapuna-puna ang relasyon
$\pm 0.91- \pm 0.99$ Napakataasnapagkakaugnay, Mapapaniwalaan ang relasyon
$\pm 1.00 \quad$ Lubos ang pagkakaugnay, Ganap na may relasyon

Talasanggunian

1. Abad, M. A., Ruedas, P. C. (2015). Filipino Bilang Tanging GamitsaPagtuturo. Brgy. San Jose, Quezon City: New Galaxie Lithographic Arts and Printing Press.

2. Badayos, P. (2012). MetodolohiyasaPagtuturo ng Wika: MgaTeorya, Simulain at Estratehiya. Manila: Granbooks Publishing Inc.

3. Byrd, P. (2012). Textbooks:Evaluation for Selection and Analysis for Implementation, Teaching of English as a Second or Foreign Language $3^{\text {rd }}$. Ed. USA: Heinle and Heinle.

4. Casiano, J. L. (2016). Hiyas ng Filipino. Quezon, City: Abiva Publishing House Inc.

5. Coker, D. L., Ritchey, K. D. (2015). Teaching Beginning Writers. New York London, The Guilford Press.Department of Education and Early Childhood development English Program (2008). Retrieved from: http://www.gov.pe.ca/educ.pdf. (January 27, 2017).

6. DepEd Order No. 13, (s.2012). "Guidelines on the Allocation, Delivery and Distribution on Instructional Material to Support the K to 12 Curriculum".Retrieved:http://www.deped.gov.ph/sites/defaultffiles/order/2012/DO_s2012_13.pdf (January 24, 2017).

7. Dulay, Tonny (2016). "Pagbuo at mgagabaysaModyul". Course Hero: Mapua Institue of Technology. https://www.coursehero.com/file/p5g0tec/Layunin-sa-Paggawa-ng-Modyul-Ang-sumusnod-ay-ang-mga-nais-maabotng-isang-gurol

8. Durante, E. B. (2014). Level of Acceptability of a Brochure as a Teaching Aid on Human Body System. Lucban, Quezon: Southern Luzon State University.Gagne, $R$. Instructional Design Theory. Retrieved from: http://nwlink.comDonclark/hrd/learning/id/ninestep_id.html (March 16, 2017)

9. Javier, E. at Castro H. (2014). Principles of Teaching 1. Manila: Rex Printing Company Inc.

10. Jumpalad, J. L. (2010). Module Preparation on Selected Topics in Biology. Lucban, Quezon: Southern Luzon State University.K to 12 GabayPangkurikulum Filipino (Baitang 1-10). (2015).Retrieved from: http://depedkurikulum.netffil_baitang_87595474.pdf(April 25, 2017)

11. Ladinez, N. H., Salipande, M. O. (2011). Proposed Module as an Instructional Material in teaching some selected topics in History of Mathematics. Lucban, Quezon: Southern Luzon State University.

12. Libby (2011). How to Create an Effective Brochure. Manila: Rex Printing Company Inc. 
13. Magsino, M. D. (2011).A Proposed Handbook of Speech Exercises Level of Oral Communication Skills. Lucban, Quezon: Southern Luzon State University.

14. Pangilinan, M. Q., Suaverdez, J. M. (2017). Development of Pamphlet as an Instructional Material in some selected topics in Science III. Lucban, Quezon: Southern Luzon State University.

15. Sharad R. (2014). How to Develop and Produce Simple Learning Materials with LimitedResources at Community Level. Retrieved from: http://www.accu.or.jp/litdbase/pub/dlperson/pdf0106/rpp25.pdf (March 11, 2017).

16. Sonne M. (2015). Low Cost Teaching and Learning Materials. Retrieved from: www.equip123.net/docs/e1emacteachersmanual.pdf (December 10, 2016).

17. Tanyag, J. B. (2012). Development and Validation of Instructional Material, A Pamphlet on the Hazardous Effects of Pesticide. Lucban, Quezon: Southern Luzon State University.

18. Villa, E. R. (2016). Teacher's Nonverbal Cues on Students Performance in Mathematics: A basis for Pamphlet Development. Lucban, Quezon: Southern Luzon State University.

19. Villasante, V. O. (2012). Development and Validation of Workbook on Selected Topics in Advanced Algebra. Lucban, Quezon: Southern Luzon State University.

20. Wolf, M. \& Gottwald, S. (To appear, 2016). What It Means to Read: A Literacy Agenda for the Digital Age. Oxford University Press. In Series, Literary Agenda, Editor: Phillip Davis.

21. Zaballero, M. C. (2012). Development and Validation of Health Teaching Pamphlet For Hyperthyroidism. Lucban, Quezon: Southern Luzon State University. 